\title{
Conditioning preparation for the nictitating membrane of the pigeon
}

\author{
KENNETH J. STICKNEY, JOHN W. DONAHOE, and NEIL R. CARLSON \\ University of Massachusetts, Amherst, Massachusetts 01003
}

\begin{abstract}
A procedure is described for restraining the pigeon while recording movement of the nictitating membrane. The preparation provides a means of studying classical conditioning that combines the rich sensory capacities of the pigeon with the control achieved in nictitating membrane conditioning of the rabbit.
\end{abstract}

We describe a preparation for classical conditioning of the nictitating membrane of the pigeon. The preparation includes methods for restraining the body, immobilizing the head, and transducing the movement of the membrane. The method of transduction is essentially identical to that used for monitoring membrane movement in the rabbit (Gormezano, Schneiderman, Deaux, \& Fuentes, 1962).

The study of classical conditioning in infrahuman organisms has been greatly facilitated by the development of the nictitating membrane preparation for the rabbit (Gormezano, 1966). With this preparation, much has been discovered about the effects of various conditioning parameters on the acquisition, maintenance, stimulus control, and extinction of responding (see Donahoe \& Wessells, 1980, for a review). Building upon this information, attention has recently shifted from the basic conditioning parameters to the more complex environmental stimulation required for the investigation of compound and second-order conditioning (e.g., Kehoe, Gibbs, Garcia, \& Gormezano, 1979; Sears, Baker, \& Frey, 1979). However, some investigators have selected other organisms for the study of complex conditioning phenomena. Notable among these organisms is the pigeon, whose sensitivity to both visual and auditory stimuli has been well documented with operant conditioning procedures (e.g., Blough, 1969; Heinemann, Chase, \& Mandell, 1968; Rilling, 1977).

Autoshaping is typically used to implement complex classical procedures with the pigeon (e.g., Rescorla, 1980; Rescorla \& Gillan, 1980). In autoshaping, a disk on the wall of the experimental chamber is illuminated immediately prior to the delivery of food to a freely moving pigeon. Conditioning is most often measured

This research was supported by NIMH Grant MH-28610 and a Biomedical Research Support Grant to the University of Massachusetts awarded to the second author. Appreciation is expressed to Susan Buccarelli for experimental assistance, to Daniel Ulrich for bringing the work of Goodson (1969) to our attention, and to Michael Crowley for the preparation of some figures. Reprints may be obtained from John W. Donahoe, Department of Psychology, University of Massachusetts, Amherst, Massachusetts 01003. by the number of pecks contacting the disk (Brown \& Jenkins, 1968). As a classical procedure, autoshaping presents substantial conceptual and methodological complexities (e.g., Gormezano \& Kehoe, 1975; Wessells, 1974), and an alternate classical procedure employing the pigeon is desirable.

\section{METHOD}

When in the retracted position, the nictitating membrane of the pigeon rests on the superior nasal portion of the eyeball. When extended, the translucent membrane moves posteriorly and laterally to cover the exposed surface of the cornea beyond the extent of the pupil (Chard \& Gundlach, 1938). The membrane is actively extended via a tendon that passes around the posterior surface of the eyeball and originates in $\mathrm{m}$. pyramidalis nictitantis. Lateral and posterior views of the tendon and associated musculature are given in Figure 1. As shown in the lateral view, $m$. pyramidalis gives rise to a tendon that passes around the optic nerve through a sling formed by $\mathrm{m}$. quadratus nictitantis. The pyramidal and quadratic muscles, both of which are innervated by the oculomotor nerve, contract together, thereby avoiding pressure on the optic nerve when the membrane is extended. As shown in the posterior view, m. pyramidalis originates from the inferior surface of the eyeball. The tendon passes beneath the eyeball and then anteriorly deep to the lower eyelid, where it inserts in the inferior margin of the nictitating inembrane (Chamberlain, 1943; George \& Berger, 1966).

\section{Restraint Procedures}

In order to monitor the movement of the nictitating membrane, it is necessary to have the position of the transducing device unaffected by head movements. This may be accomplished by affixing the transducer to the head of the animal, as is done in the rabbit preparation, or by restraining the head. Because of the smaller and more fragile avian skull, restraint was the method selected for the pigeon preparation.

The body and head are restrained by separate devices attached to vertical rods separated by $45 \mathrm{~cm}$ and threaded into a common base plate. The bottom and top of a $2-q t$ plastic container (such as that used for laundry bleach) are cut off, allowing the pigeon to be inserted from the bottom with its head and neck protruding through the smaller top opening. Holes drilled in the sides of the container facilitate conduction of body heat away from the bird. A longitudinal slit, running from the bottom to onethird of the way to the top, is made in the plastic container. This slit permits the circumference of the bottom of the container to be reduced, thereby preventing the pigeon from withdrawing from the container. The container is then suspended from a nearly horizontal rod attached to one of the vertical rods by means of a ringstand clamp. 

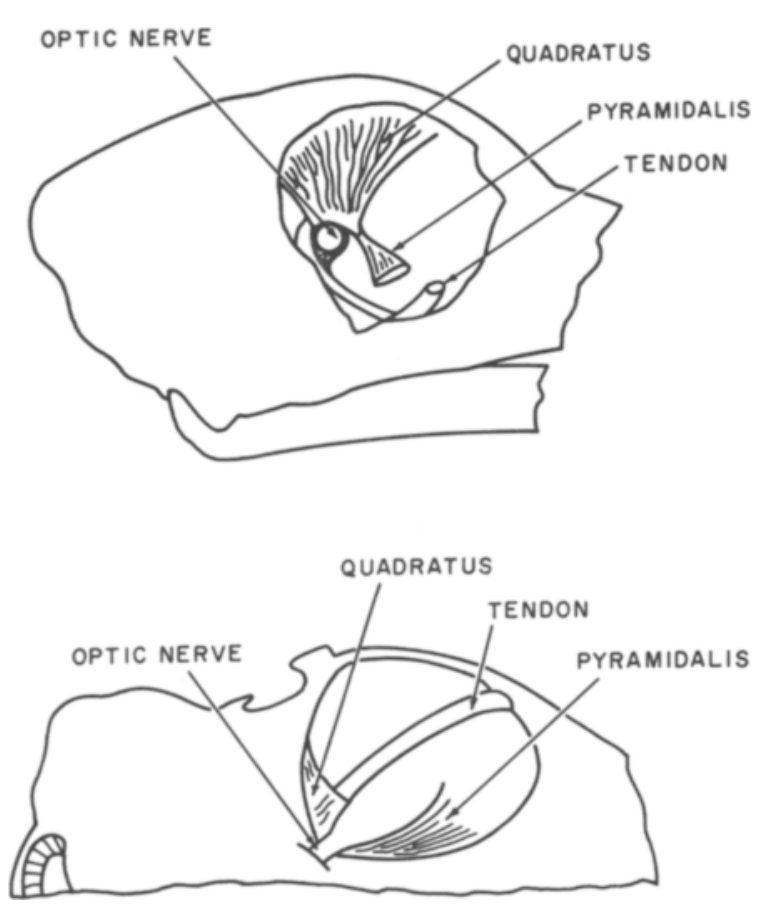

Figure 1. Lateral (upper drawing) and posterior (lower drawing) views of the musculature and tendon causing extension of the avian nictitating membrane. The rectus and oblique muscles causing movement of the eyeball have been dissected away for these drawings (after George \& Berger, 1966).

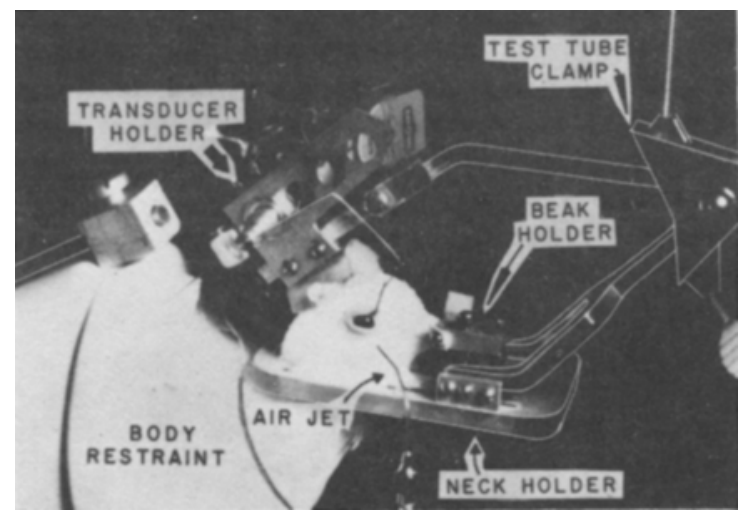

Figure 2. Photograph of a pigeon in the restraint device. The body is restrained by a plastic container. Head movement is restricted by the neck holder, beak holder, and transducer holder. Also mounted on the transducer holder is the rotary potentiometer monitoring movement of the nictitating membrane. The air jet supplied the US.

The head restraint restricts movement at three points-the base of the skull, the mandibles, and the top of the skull. These components of the head restraint system are referred to as the neck holder, the beak holder, and the transducer holder, respectively. The three components are attached to a three-prong test-tube clamp (Fisher 05-742) by means of machined fittings using set screws (see Figure 2). (Since the test-tube clamp is a casting, it may not readily be tapped and threaded.) The testtube clamp is attached to the second vertical rod by means of a swivel ringstand clamp (Fisher 05-762).
Once the body of the pigeon has been restrained, the neck holder is put into place. The neck holder is cut from a $1 / 4$-in.thick plastic sheet and has a curved channel and a straight slot (see Figure 3). The neck holder is attached to a fitting on one prong of the two-prong arm of the test tube clamp by means of two screws in the straight slot. With the head holder in the position shown in Figure 3, the neck of the pigeon is moved to the rear of the curved channel and the holder is moved forward until the other prong of the two-prong arm blocks withdrawal of the neck (cf. Goodson, 1969; Ulrich, Blough, \& Blough, in press). The nuts on the machine screws that pass through the slot are tightened to prevent further movement of the neck holder.

When the neck holder is in place, the beak holder is attached. The beak holder is mounted on stand-offs to the same fitting used to secure the neck holder (see Figure 3). The metal block from which the beak holder is made has a tapered groove into which the upper mandible fits. The upper mandible is inserted in to the groove until the wattles almost touch the beak holder. The beak is then maintained in the groove by a 4-mm-wide rubber band. The taut rubber band is secured on both ends against the sides of the beak holder by a small clamp.

After the neck holder and beak holder are in place, the thumbscrew controlling the position of the single-prong arm of the test tube clamp is turned until the transducer holder fits snugly against the top of the skull (see Figure 2). The transducer holder is attached to the single-prong arm by means of a fitting and consists of a $55-\mathrm{mm}$ extension rod on which are mounted two parts-a curved plate attached below a second fitting secured to the extension rod and a vertical plate attached above that same fitting. The curved plate restrains head movement and is lined with foam rubber on the surface that contacts the top of the bird's head (see Figure 2). The curved plate is formed from $25 \mathrm{~mm} \times 30 \mathrm{~mm}$ sheet metal bent such that the edges of the longer side are $24 \mathrm{~mm}$ apart. The vertical plate has noncritical dimensions and serves as a platform on which are mounted the transducing mechanism and any other components.

When the head has been secured by all three holders, the device for transducing movement of the nictitating membrane is attached. By means of a mechanical linkage, movements of the membrane cause the shaft of a minitorque potentiometer to rotate. The potentiometer is mounted on the vertical plate that forms the upper part of the transducer holder. The movement of the shaft changes the voltage across the potentiometer, supplying a signal that varies with the position of the membrane.

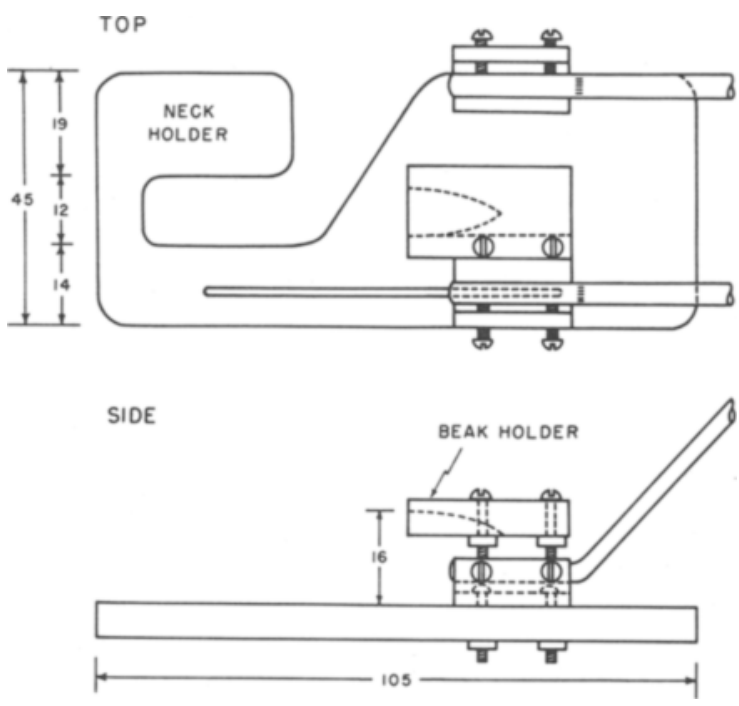

Figure 3. Top and side scale drawings of the neck and beak holders. All measurements are millimeters. 
The mechanical linkage is accomplished as follows. After a topical anesthetic has been applied to the eye, the membrane is lifted off the eyeball by forceps and a suture of 6-0 silk surgical thread is placed near the free margin. The suture passes through the membrane, returns through the tissue, and is tied on the exterior surface of the membrane. A small loop in the suture is then formed by a second knot. A steel hook is inserted in the loop, the hook is attached by a short length of surgical thread to a thin stiff wire, and finally the wire is attached at right angles to the shaft (cf. Gormezano, 1966). As shown in Figure 2, transduction of the membrane leaves the lateral visual field unobstructed.

\section{APPLICATION}

Over a dozen birds in a variety of experimental conditions have been used in various phases of the development of the nictitating membrane preparation for the pigeon. Pigeons adapt readily to restraint with the described methods (cf. Cohen \& Macdonald, 1971). Animals have been restrained for sessions lasting as long as $3 \mathrm{~h}$ and for as many as 18 sessions.

CRs develop within 50-100 trials with the conditioning parameters given below (cf. Davis \& Coates, 1978). A $250-\mathrm{msec}$ CS.US interval is employed in a delay paradigm with a variable intertrial interval of $60 \mathrm{sec}$. Fifty trials constitute a session. The CS duration is $350 \mathrm{msec}$, and the US duration is $100 \mathrm{msec}$. Auditory and visual CSs are employed. The auditory CS is a $950-\mathrm{Hz}$ tone at $85 \mathrm{~dB}$. The visual CS consists of the illumination of an $18 \times 22 \mathrm{~cm}$ red panel at a distance of $21 \mathrm{~cm}$. The onset of the CS increases the illumination to $42 \mathrm{~cd} / \mathrm{m}^{2}$ from a background level of $4 \mathrm{~cd} / \mathrm{m}^{2}$ provided by a diffuse white houselight in the sound-attenuating experimental chambers. The US is a puff of air to the cornea from a 20-gauge needle at a distance of $5 \mathrm{~mm}$ from the cornea with a pressure of $20 \mathrm{psi}$.

With these same parameters, CRs occur approximately $120 \mathrm{msec}$ after CS onset and, at asymptotic conditioning levels, blend with the UR. A record from a storage oscilloscope of an early-appearing CR is shown in Figure 4. (The rapid rise time of the membrane response causes an overshoot in the record unless transducer movement is damped.)

The asymptotic percentage of CRs is in excess of $90 \%$ and is reached after 200-300 trials. The maximum amplitude of the conditioned membrane response is somewhat greater than $6 \mathrm{~mm}$ and occurs near US onset, as measured during occasional trials in which the $\mathrm{CS}$ was presented alone.

Reflexive responses to CS onset (alpha responses) have not yet been assessed with pigeons exposed exclusively to CS-alone trials. However, as assessed with pigeons given CS-US pairings or unpaired CS-US presentations, membrane responses occurring shortly after CS onset early in training are rare.

Finally, the level of spontaneous membrane responses is low as assessed during the intertrial interval, both for birds given CS-US pairings and for birds given unpaired CS-US presentations. Using measurement periods during

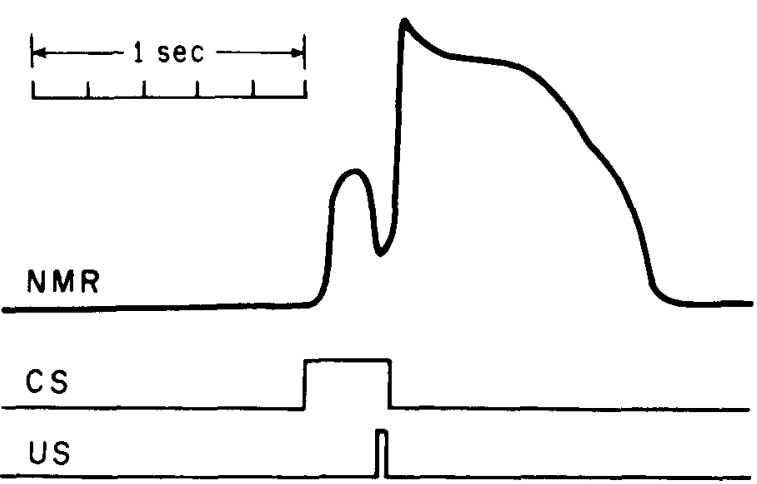

Figure 4. An oscilloscope tracing of a nictitating membrane response (NMR) occurring on an early conditioning trial. Responses on later trials blend with the UR.

the intertrial interval of the same duration as the CS, spontaneous responses occur during 5\%-10\% of the periods for different birds and with a mean amplitude of approximately $2 \mathrm{~mm}$.

\section{SUMMARY}

The nictitating membrane response of the pigeon provides an attractive preparation, especially when complex stimulus displays must be implemented as in the study of compound and second-order conditioning. The animal adapts well to restraint, conditioning develops rapidly, and asymptotic performance is high with acceptable levels of spontaneous and alpha responding.

\section{REFERENCES}

Blough, D. S. Attention shifts in a maintained discrimination. Science, 1969, 166, 125-126.

Brown, P. L., \& Jenkins, H. M. Autoshaping of the pigeon's key-peck. Journal of the Experimental Analysis of Behavior, 1968, 11, 1-6.

Chamberlain, F. W. Atlas of avian anatomy. Lansing, Mich: Hallenbeck, 1943.

Chard, R. D., \& Gundlach, R. H. The structure of the eye of the homing pigeon. Journal of Comparative Psychology, $1938,25,249-272$.

Cohen, D. M., \& Macdonald, R. L. Some variables affecting orienting and conditioned heart-rate responses in the pigeon. Journal of Comparative and Physiological Psychology, 1971, 74, 123-133.

Davis, J. L., \& Contes, S. R. Classical conditioning of the nictitating membrane in the domestic chick. Physiological Psychology, 1978, 6, 66-71.

Donahoe, J. W., \& Wessells, M. G. Learning, language, and memory. New York: Harper \& Row, 1980.

George, J. C., \& Berger, A. J. Avian myology. New York: Academic Press, 1966.

Goobson, J. E. Optokinetic responses in the pigeon. Unpublished doctoral dissertation, George Washington University, 1969.

Gormezano, I. Classical conditioning. In J. B. Sidowski (Ed.), Experimental methods and instrumentation in psychology. New York: McGraw-Hill, 1966.

Gormezano, I., \& Kenoe, E. J. Classical conditioning: Some methodological and conceptual issues. In W. K. Estes (Ed.), Handbook of learning and cognitive processes (Vol. 2). Hillsdale, N.J: Erlbaum, 1975. 
Gormezano, I., Schneiderman, N., Deaux, E., \& Fuentes, I. Nictitating membrane: Classical conditioning and extinction in the albino rabbit. Science, 1962, 138, 33-34.

Heinemann, E. G., Chase, S., \& Mandell, C. Discriminative control of "attention." Science, 1968, 60, 553-554.

Kehoe, E. J., Gibbs, C. M., Garcia, E., \& Gormezano, I. Associative transfer and stimulus selection in classical conditioning of the rabbit's nictitating membrane response to serial compound CSs. Journal of Experimental Psychology: Animal Behavior Processes, 1979, 5, 1-18.

Rescorla, R. A. Pavlovian second-order conditioning: Studies in associative learning. Hillsdale, N.J: Erlbaum, 1980.

Rescorla, R. A., \& Gillan, D. J. An analysis of the facilitative effect of similarity on second-order conditioning. Journal of Experimental Psychology: Animal Behavior Processes, 1980, 6, 339-351.
RILling, M. E. Stimulus control and inhibitory processes. In W. K. Hongi \& J. E. R. Staddon (Eds.), Handbook of operant conditioning. Englewood Cliffs, N.J: Prentice-Hall, 1977.

Sears, R. J., Baker, J. S., \& Frey, P. W. The eyeblink as a time-locked response: Implications for serial and second-order conditioning. Journal of Experimental Psychology: Animal Behavior Processes, 1979, 5, 43-64.

Ulrich, D., Blough, P., \& Blough, D. The pigeon's distant visual acuity as a function of visual angle. Vision Research, in press.

Wessells, M. G. The effects of reinforcement upon the prepecking behavior of pigeons in the autoshaping experiment. Journal of the Experimental Analysis of Behavior, 1974, 21, $125-144$.

(Received for publication April 15, 1981; revision accepted July 15,1981 .) 